\title{
Larval and phenological traits predict insect community response to mowing regime manipulations
}

\author{
Roel van Klink iD , ${ }^{1,7,10}$ Myles H. M. Menz (iD) $2,3,8$ Hannes Baur, ${ }^{2,4}$ Oliver Dosch, ${ }^{1}$ Isabel Kühne, \\ Lukas Lischer, ${ }^{1}$ Henryk Luka, ${ }^{5}$ Sandro Meyer, ${ }^{1,9}$ Timea Szikora, ${ }^{1}$ Debora Unternährer, ${ }^{1}$ Raphaël Arlettaz, ${ }^{1,6}$ \\ AND JEAN-YVES HUMBERT ${ }^{1}$ \\ ${ }^{1}$ Division of Conservation Biology, Institute of Ecology and Evolution, University of Bern, Balzerstrasse 6, 3012 Bern Switzerland \\ ${ }^{2}$ Division of Community Ecology, Institute of Ecology and Evolution, University of Bern, Balzerstrasse 6, 3012 Bern Switzerland \\ ${ }^{3}$ School of Biological Sciences, The University of Western Australia, Crawley, Western Australia 6009 Australia \\ ${ }_{5}^{4}$ Department of Invertebrates, Natural History Museum Bern, Bernastrasse 15, 3005 Bern, Switzerland \\ ${ }^{5}$ Department of Crop Sciences, Research Institute of Organic Agriculture FiBL, 5070 Frick Switzerland \\ ${ }^{6}$ Swiss Ornithological Institute, Valais Field Station, Rue du Rhône 11, 1950 Sion Switzerland
}

Citation: van Klink, R., M. H. M. Menz, H. Baur, O. Dosch, I. Kühne, L. Lischer, H. Luka, S. Meyer, T. Szikora, D. Unternährer, R. Arlettaz, and J.-Y. Humbert. 2019. Larval and phenological traits predict insect community response to mowing regime manipulations. Ecological Applications 29(4):e01900. 10.1002/eap.1900

Abstract. For the restoration of biodiversity in agricultural grasslands, it is essential to understand how management acts as an ecological filter on the resident species. Mowing constitutes such a filter: only species that possess functional traits enabling them to withstand its consequences can persist in the community. We investigated how the timing of mowing modulates this filtering effect for insects. We predicted that two traits drive species responses. Species with larval development within the meadow vegetation will suffer more from mowing than species whose larvae develop in or on the ground, or outside the meadows, while species with a later phenology should benefit from later mowing. We conducted a five-year experiment, replicated at 12 sites across the Swiss lowlands, applying three different mowing regimes to lowintensity hay meadows: (1) first cut of the year not earlier than 15 June (control regime); (2) the first cut delayed until 15 July; and (3) leaving an uncut grass refuge on 10-20\% of the meadow area (after earliest first cut on 15 June). Before the first cut in years 4 or 5 , we sampled larvae of Lepidoptera and sawflies, and adults of moths, parasitoid wasps, wild bees, hoverflies, ground beetles, and rove beetles. Overall, before the first cut of the year, abundances of species with vegetation-dwelling larvae were higher in meadows with delayed mowing or an uncut grass refuge, with some taxon-specific variation. In contrast, species whose larval development is independent of the meadow vegetation showed no differences in abundance between mowing regimes. Species richness did not differ among regimes. For species with vegetation-dwelling larvae, a fourth-corner analysis showed an association between early phenology and the control regime. No associations were found for the other functional groups. Our results show that slight modifications of mowing regimes, easily implementable in agri-environmental policy schemes, can boost invertebrate abundance, potentially benefitting insectivorous vertebrates.

Key words: cutting; ecological filter; fourth-corner analysis; grassland; invertebrates; mowing date; multiabundance; multidiversity.

\section{INTRODUCTION}

With the ongoing attrition of biological diversity across the planet, it is becoming increasingly important

Manuscript received 27 June 2018; revised 30 December 2018; accepted 20 February 2019. Corresponding Editor: Elisabeth Huber-Sannwald.

${ }^{7}$ Present address: German Centre for Integrative Biodiversity Research iDiv, Deutscher Platz 5e, 04103 Leipzig Germany

${ }^{8}$ Present address: Department of Migration and Immunoecology, Max Planck Institute for Ornithology, 78315 Radolfzell Germany

${ }^{9}$ Present address: Department of Environmental Sciences, Section of Conservation Biology, University of Basel, St. Johanns-Vorstadt 10, 4056 Basel Switzerland

${ }^{10}$ E-mail: roel.klink@idiv.de to understand and mitigate the impacts of land-use changes on ecological communities. The concept of ecological filtering (Woodward and Diament 1991, Keddy 1992) is useful for investigating patterns of community assembly under natural or anthropogenic stressors. According to this concept, ecological communities are shaped by a number of overlapping filters, set by dispersal barriers, local abiotic conditions and biotic interactions, with only species possessing certain key traits being able to persist in the local community. For invertebrates in seminatural grasslands, anthropogenic land management constitutes one of these principal filters (Simons et al. 2017).

In Europe, seminatural grasslands are typically managed by mowing and/or livestock grazing, often in 
combination with fertilization. The ongoing intensification of these practices via increased fertilizer application, higher cutting frequencies and higher livestock densities, has negatively impacted grassland biodiversity (e.g., Kleijn et al. 2009, Allan et al. 2014, Uchida and Ushimaru 2014) and led to biotic homogenization across many plant and animal taxa (Uchida and Ushimaru 2015, Gossner et al. 2016). For invertebrates, management intensification has been shown to favor species that are smaller in size, ecologically less specialized, and have a greater dispersal capacity (Blake et al. 1994, Woodcock et al. 2009, Cardarelli and Bogliani 2014, Lafage and Pétillon 2014, Birkhofer et al. 2015, Simons et al. 2017).

To develop a predictive framework of invertebrate community assembly in managed grasslands, we need to obtain a mechanistic understanding of species responses to different management practices, modulated by their functional traits. In this paper, we focus on the effects of mowing. Mowing is not only a common harvesting method to produce hay or silage for winter livestock feed, but in Europe, it is also commonly applied to preserve seminatural habitats of conservation concern, as it prevents bush encroachment and typically maintains a high botanical diversity (Bakker 1989). However, mowing is also characterized by a sudden homogeneous reduction in vegetation height, which usually has strong direct negative effects on grassland invertebrates (Löbbert et al. 1994, Williamson and Potier 1997, Humbert et al. 2009, 2010a,b, Lafage and Pétillon 2014). In particular to species that live and reproduce in the vegetation, mowing operations can cause direct mortality up to $90 \%$ (Löbbert et al. 1994, Humbert et al. 2010a). Furthermore, mowing is followed by a period of low resource availability (Völkl et al. 1993, Callaham et al. 2002), a harsher microclimate (Wan et al. 2002, Gardiner and Hassall 2009), and increased predation risk (Arlettaz 1996, Devereux et al. 2006), which causes additional mortality to aboveground invertebrates. Thus, as mowing frequency increases, ecological filtering should also become stronger, with detrimental consequences for grassland biodiversity (Helden and Leather 2004, Allan et al. 2014, Uchida and Ushimaru 2014).

Since the loss of each (sub-) adult individual to grassland management also means the loss of its reproductive potential, mowing induced mortality severely reduces populations of grassland invertebrates (Humbert et al. $2009,2010 b$ ). If mowing is delayed, this should thus allow more individuals to reproduce before cutting, and larger numbers of eggs or larvae of the next generation may survive the cutting process. This, in turn, should lead to an increase in invertebrate abundance and species richness in the following year before cutting, with populations progressively increasing over the years (Buri et al. 2013, Bruppacher et al. 2016). In contrast, species that occur in meadows only as adults (e.g., insects with larval stages in trees and bushes but whose adults collect nectar from meadow flowers) would not be expected to respond strongly to changes in the cutting date, at least not before mowing takes place. Species with larvae living in the soil or on the soil surface will not be directly affected by mowing, but may be affected indirectly by concomitant changes in environmental conditions such as microclimate or food availability.

To test these predictions about community filtering, we conducted a manipulative field experiment in agriculturally used hay meadows from 2010 to 2015 . We compared control meadows, where the first cut of the year took place around mid-June, with meadows in which the first cut was postponed by one month (i.e., mid July) and meadows in which an uncut grass refuge was retained on $10-20 \%$ of the meadow area between mowing events. Meadows were usually cut a second time in August-September. These two altered mowing regimes thus consisted of either a moderate delay of the first mowing event over the whole meadow area, or a longer delay of the first mowing event (up to three months) restricted to a small fraction of the meadow.

Specifically, we tested the following hypotheses:

1) Species with larval development in the vegetation column will benefit from delayed mowing, as they will have a longer period for reproduction before the first cut. This will be reflected by a greater abundance and species richness of these species in the meadows with altered mowing regimes. Species with soil- or grounddwelling larvae, as well as species reproducing outside the meadows will show weaker responses, if any. As no changes in the plant community were detected (Van Klink et al. 2017), the effects on insects should be a result of the mowing regimes, and not of changes in vegetation composition.

2) Species with a later phenology (i.e., start of adult activity) will benefit from delayed mowing, since they have a longer period to reach reproductive maturity. Hence, there should be an association between species with a later phenology and the alternative mowing regimes.

As we were interested in legacy effects of alternative mowing regimes over the years (i.e., effects of the management in previous years carrying over to the present), and not in the direct effects of mowing, we sampled insects before the first cut in the fourth and fifth years of the experiment. We sampled a broad palette of holometabolic insect taxa, exhibiting a diverse range of life-history and trophic strategies: larvae of Lepidoptera and sawflies, adult night active Lepidoptera (hereafter moths), parasitoid wasps, hoverflies, wild bees, ground beetles, and rove beetles.

\section{Methods}

\section{Site description and experimental design}

Twelve study areas, spaced between 5 and $195 \mathrm{~km}$ apart, were selected on the Swiss Plateau, the lowland 
region situated between the Jura Mountains and the Alps. These sites represent a typical example of the Western-/Central-European agricultural landscape, where high-intensity agriculture (about $70 \%$ of the matrix) is interspersed with human settlements, industry, infrastructure, and forest stands. In each study area, three meadows with a minimum size of 0.3 ha (mean 0.8 ha, maximum $1.7 \mathrm{ha}$ ), located within a radius of $3.5 \mathrm{~km}$ and spaced at least $440 \mathrm{~m}$ apart, were selected for the experiment. All experimental meadows had been registered under the Swiss agri-environment scheme as "extensively managed hay meadows" since latest 2004. Under this scheme the first possible mowing date was 15 June, while neither fertilizer nor pesticide application was allowed. The elevation of the sites ranged from 390 to $826 \mathrm{~m}$, annual precipitation from 845 to $1,148 \mathrm{~mm}$, and mean annual temperature from $13.7^{\circ}$ to $16.3^{\circ} \mathrm{C}$. Appendices 1 and 2 in Buri et al. (2016) provide a map and the coordinates of the study sites, respectively.

One of the three following mowing regimes was randomly allocated to each of the three meadows per study area, and implemented from 2010 onward: (1) Control: first cut not before 15 June, but no restrictions on the number and frequency of subsequent cuts; no application of fertilizer or pesticides allowed. (2) Delayed: as control, but with the first cut delayed by one month, to 15 July. (3) Refuge: as control, but $10-20 \%$ of the meadow area was left uncut each time the meadow was mown. The location of this refuge within the meadow was chosen freely by the farmers, but was changed between successive cuts.

Meadows were cut with a rotary mower. The first annual cut was harvested in the form of hay (dry forage) while the second in the form of hay or silage (fermented forage). Mowing was conducted up to the edge of the meadow, so that no accidental refuge was present. Furthermore, road verges and ditch banks in the surrounding area are typically cut more frequently than hay meadows (although this was not recorded). Afterward, grazing was allowed between 1 September and 30 November in all meadows, although not applied consistently across the study sites (Table 1). The implementation of the mowing regimes (mowing dates, and grazing events) was recorded using yearly questionnaires to the farmers. The variability in regime application over
2010-2015 is summarized in Table 1, and was accounted for in the analyses. One site was converted into a gravel pit in 2012, leaving 35 experimental meadows.

\section{Insect sampling}

The seven selected insect taxa were sampled before the first mowing operations took place (i.e., before 15 June) of years 4 (2014) or 5 (2015) of the experiment. We included a broad palette of taxa, exhibiting a diverse range of life-history and trophic strategies: species (almost) certainly reproducing in the meadow vegetation (larvae of Lepidoptera and sawflies [Hymenoptera: Symphyta] and parasitoid wasps [Hymenoptera: Parasitica]); mobile species that perform important ecosystem functions (hoverflies [Diptera: Syrphidae], wild bees [Hymenoptera: Apocrita: Anthophila], and adult night-active Lepidoptera [hereafter moths]); and ground-dwelling arthropods (ground beetles [Coleoptera: Carabidae] and rove beetles [Coleoptera: Staphylinidae]).

Caterpillars of macrolepidoptera and sawflies were sampled between 28 May and 12 June 2015. Each meadow was sampled once in the morning (09:30-12:30) and once in the afternoon (16:00-19:00). The larvae were sampled through sweep netting along predetermined 60$\mathrm{m}$ transects, located centrally along the longest diagonal of each meadow. Along each transect, 120 sweeps were performed. The two sampling sessions per meadow occurred on the same day, if possible. The larvae caught were individually photographed and stored for later identification. Lepidopteran larvae were identified to species level but sawfly larvae were not identified further.

Adult moths (night active Lepidoptera) were sampled twice in each meadow in 2014 using light traps. A 15-W black light was positioned at the center of each meadow, $1.6 \mathrm{~m}$ above the ground. To reduce the attraction range of the traps, the top one-half of the surface of the light bulbs was masked, resulting in an approximate power of $7.5 \mathrm{~W}$. The traps were active for five hours, starting at nightfall, with the three meadows in each region sampled on the same night. All macro-moths were identified to species level.

Hoverflies (Diptera: Syrphidae) and wild bees (Hymenoptera: Apoidea: Anthophila) were sampled in 2014

TABLE 1. Summary of the mowing regimes.

\begin{tabular}{|c|c|c|c|c|c|}
\hline \multirow[b]{2}{*}{ Mowing regime } & \multicolumn{2}{|c|}{ 2010-2015 } & \multirow[b]{2}{*}{ No. cuts/yr } & \multirow{2}{*}{$\begin{array}{c}\text { No. weeks } \\
\text { (second - first cut) }\end{array}$} & \multirow{2}{*}{$\begin{array}{c}\text { No. grazed } \\
\text { meadows }\end{array}$} \\
\hline & First cut & Second cut & & & \\
\hline Control & $171.2 \pm 7.6$ & $237.5 \pm 17.7$ & $1.9 \pm 0.1$ & $9.5 \pm 0.7$ & $4-8$ \\
\hline Delayed & $203.3 \pm 9.6$ & $259 \pm 24.5$ & $1.4 \pm 0.2$ & $8.0 \pm 1.2$ & $4-7$ \\
\hline Refuge & $170.7 \pm 4.4$ & $231.9 \pm 16.6$ & $2.1 \pm 0.1$ & $8.7 \pm 0.6$ & $6-9$ \\
\hline
\end{tabular}

Notes: Values are mean $\pm \mathrm{SD}$ of the ordinal day of the first and second cut (average over 2010-2015), the number of cuts per year, and the number of weeks between the first two cuts. Note that several control and delayed meadows were cut three times per year. The number of meadows grazed in autumn are given in the last column (range 2010-2015 out of 11 delayed or 12 control or 12 refuge meadows). 
and 2015, respectively. Both groups were collected using two complementary methods (Grundel et al. 2011): colored pan traps and sweep netting (see Meyer et al. 2017 for more details on the methodology). Briefly, in the center of each meadow, three sets of three pan traps (yellow, white, and blue) were attached to wooden poles and arranged in a triangular pattern. Two sweep-net transects of $30 \mathrm{~m}$ (representing 30 sweeps each) were carried out along the sides of the triangle made by the pan traps. Pan traps were exposed to pollinating insects for one day, and sweep netting was performed on a different day. All specimens were identified to species level in the laboratory. For this analysis, the data of both trapping methods were pooled. Analyses separated between the methods and on the effects after the first cut can be found in Meyer et al. (2017).

Ground beetles (Coleoptera: Carabidae) and rove beetles (Coleoptera: Staphylinidae excluding Pselaphinae) were caught by pitfall-trapping for two weeks (11 May29 May 2015). In each meadow, four pitfall traps (outer diameter $9 \mathrm{~cm}$ ) were installed in a square, spaced $10 \mathrm{~m}$ apart. To protect the traps from rain, $20 \times 20 \mathrm{~cm}$ transparent transparent plastic covers were installed above every trap. The traps were filled with propylene glycol diluted with water (ratio 2:1) as a killing and preserving agent, and were emptied weekly. All ground and rove beetles were identified to species level. Despite the use of covers, in 23 out of 280 trapping weeks (35 meadows $\times 4$ traps $\times 2$ weeks), small mammals (voles and shrews) were caught. Such a carrion source is highly attractive to some rove beetle species and therefore the affected traps were excluded from analysis. To avoid biases due to unequal trapping effort, we used a randomization procedure to select six out of eight trap weeks in each meadow. This was repeated 999 times to derive median values for the number of individuals and species. Despite this subsampling strategy, two meadows had to be excluded from the analysis of these taxa because mammals were caught in four trap-weeks, leaving 33 meadows.

Pteromalidae and other parasitoid Hymenoptera were collected by sweep netting in 2014. In each meadow, two 25-m transects were randomly laid out and 30 net strokes were performed along each transect. To avoid capture of larger insects, the triangular net (design Noyes 2017) was equipped with a 6-mm stainless steel mesh. The net was emptied every 10 strokes and all parasitoid wasps were collected using an aspirator. All individuals were identified to family level (Goulet and Huber 1993) and Pteromalidae were identified to genus level in the lab.

Literature used for the identification of all taxa can be found in Appendix S1: Table S1.

\section{Traits}

All taxa were divided into three functional groups based on their larval substrate: (1) species that could have completed their larval development in the vegetation column of the meadow; (2) species that could have developed in or on the soil of the meadows; and (3) species that could not have completed their larval development in the meadow itself as they depend on, e.g., woody vegetation for feeding (larval stage) or nesting, but may visit meadows for feeding once adult. All larvae of Lepidoptera and sawflies were classified as vegetation-dwelling. The parasitoid wasps were not identified to species level, but assumed to have vegetation-dwelling larvae as well, given their mostly limited mobility. Moths were classified based on their larval host plants according to Ebert et al. (1994-2003): species feeding on grasses or forbs were classified as vegetation-dwelling, whereas species feeding on trees, shrubs (e.g., Rubus), lichens, or forbs that are typically never found in meadows (i.e., Pteridium aquilinum, Urtica dioica) were classified as reproducing outside the meadows (see Van Klink et al. [2017] for a list of plant species occurring in our experimental meadows). Wild bees were divided into ground-nesting species (classified as soil-dwelling) or species nesting in woody structures (classified as outside meadow) following Amiet et al. (1996-2010; references in Appendix S1: Table S1). Hoverflies were split into two groups: predatory and herbivorous species were classified as vegetation-dwelling, while detritivorous species (including species with aquatic larvae) and species mostly found on trees were classified as "outside meadow," following Reemer et al. (2009). For ground beetles, which are often flightless, and rove beetles, of which the larval habitat preferences are poorly known, we assumed all species to have completed their larval development within the meadows, classifying them as soil-dwelling. Both adults and larvae of these taxa usually spend at least part of their diurnal cycle below ground, in crevices or under objects, making them less susceptible to the direct effects of mowing.

Species phenology was measured on a continuous scale as the start of adult activity. For all species, this phenological information was obtained from the literature from Switzerland or the neighboring German state of Baden-Württemberg. Depending on the level of detail available, species-specific phenology was classified in the following way: middle of the month for ground beetles (Luka et al. 2009) and rove beetles (H. Luka, P. Nagel, A. Luka, and Y. Gonseth, unpublished data) or per approximate week of the month for hoverflies (Maibach et al. 1992), wild bees (Westrich 1989, Amiet et al. 1996-2010), and moths (Ebert et al. 1994-2003). Moth phenology was obtained from capture dates averaged across four regions of Baden-Württemberg (excluding the region Oberrheinebene because of its much lower elevation, $<300 \mathrm{~m}$, than our experimental meadows). These sources are all based on hundreds of specimens caught (see Appendix S1: Table S2 for the full species list, larval substrate, and all phenological data). No phenological data could be derived for parasitoid wasps and sawflies, 
as they were not identified to species level. All data are available in Data S1.

\section{Statistical analysis}

All analyses were performed on samples combined at the meadow level, i.e., pooling all transects, subplots, or traps from a given meadow. To obtain synthetic measures of species richness and abundance for each functional group per meadow, we used the multidiversity concept of Allan et al. (2014). Multidiversity was calculated by scaling the species richness of each taxon by the mean of the three maximum observed values, taking the mean of these scaled values across all taxa within the functional group (adapted from Allan et al. 2014). We extended this concept to calculate a multiabundance index, which corresponded to a scaled metric for total number of individuals. This way all taxa were given the same weight, independent of their total richness or abundance.

We tested for the effects of the mowing regimes using generalized linear mixed models (GLMM). These models included mowing regime, number of meadow uses (number of cuts + number of grazing events) and time (number of days) between the first and second cuts in the year prior to sampling as fixed variables, and study area as a random factor. Differences in multidiversity and multiabundance among the mowing regimes were tested for using models with a Gaussian error distribution, where for the number of cuts and time between cuts we used the means over 2010-2015. We used backward model selection based on $P$ values of the individual variables to derive the best fitting models. Data points for which number of uses or days between cuts was unknown (because questionnaires were not returned) were omitted depending on model structure. Since abundance data typically show overdispersion of the residuals, we used penalized quasi-likelihood (PQL) regression with a quasi-Poisson distribution, in cases of overdispersion (model specifications are given in Table 2). Models for species richness did not show overdispersion and were therefore all fitted using maximum likelihood estimation with a Poisson error distribution. For the randomized data obtained for ground and rove beetles (to account for lost traps), the median abundance and species richness of 999 iterations per meadow were used as the input for the linear models. All pairwise contrasts between the three regimes were tested using Tukey's post-hoc tests, correcting $P$ values for false positives using false-discovery rate correction (FDR; Benjamini and Hochberg 1995).

To test for an association between phenology and our mowing regimes, we used a fourth-corner analysis (Legendre et al. 1997, Dray and Legendre 2008). This is a multivariate method that tests for associations between environmental conditions and species' traits, connecting traits and environment through the species by site matrix. $P$ values are calculated using a permutational approach, which either randomizes species or sites These tests can, therefore, not distinguish whether an association with the environment is found because of effects of the species composition or the traits associated with this species composition. To account for this, we first tested if there was indeed no association between the species composition and the mowing regimes, which is what we expected, since the large geographical gradient tested would probably have a stronger influence on species composition than the mowing management. We tested this using permutational multivariate ANOVA. We then used the fourth-corner analysis to test whether the traits, which are fixed to the species, are linked to the mowing regimes. This was tested by randomizing the environmental variables (mowing regimes as rows of the species by site matrix) across the species composition (permutation model 2 in Dray and Legendre 2008). The $P$ values were again adjusted for multiple comparisons by FDR. Only taxa with species level identification and phenological information per species (wild bees, hoverflies, adult moths, lepidopteran larvae, ground beetles, and rove beetles) were included in this analysis. To account for differences in catch rates of the various sampling methods, the matrices of each of the input taxa were scaled to the maximum observed value, giving values between 0 and 1 . These scaled matrices of the separate taxa were joined into a large matrix per functional group. The analysis was conducted separately for each functional group, since we were only interested in treatment (mowing regime) effects within the functional group and not in comparing the groups.

For the species whose larvae develop in the vegetation column or outside the meadow, the fourth-corner analysis was run with 99,999 permutations. For the analysis of the soil-dwelling species, which included all ground and rove beetles, we ran the fourth-corner analysis 999 times with 999 permutations, each time randomly selecting six trapping weeks per meadow to account for lost traps. The results of the fourth-corner analysis were visualized by plotting the number of individuals with an early phenology (before June) and a late phenology (from June onward) over the three mowing regimes.

All analyses were performed in R 3.4.3, using the libraries MASS (Venables and Ripley 2002) for PQL regression, lme4 (Bates et al. 2014) for maximum likelihood regression, ade4 (Dray and Dufour 2007) for fourth-corner analysis, and vegan (Oksanen et al. 2017) for the permutational multivariate ANOVA analysis.

\section{Results}

We collected a total of 10,716 insects, which were identified to 23 species of lepidopteran larvae, 90 adult moth species, 47 wild bee species, 28 hoverfly species, 65 ground beetle species, 91 rove beetle species, 18 families of parasitoid wasps, with 18 genera of Pteromalidae (for more details see Appendix S2: Table S1). A small number of individuals that could not be identified to species 


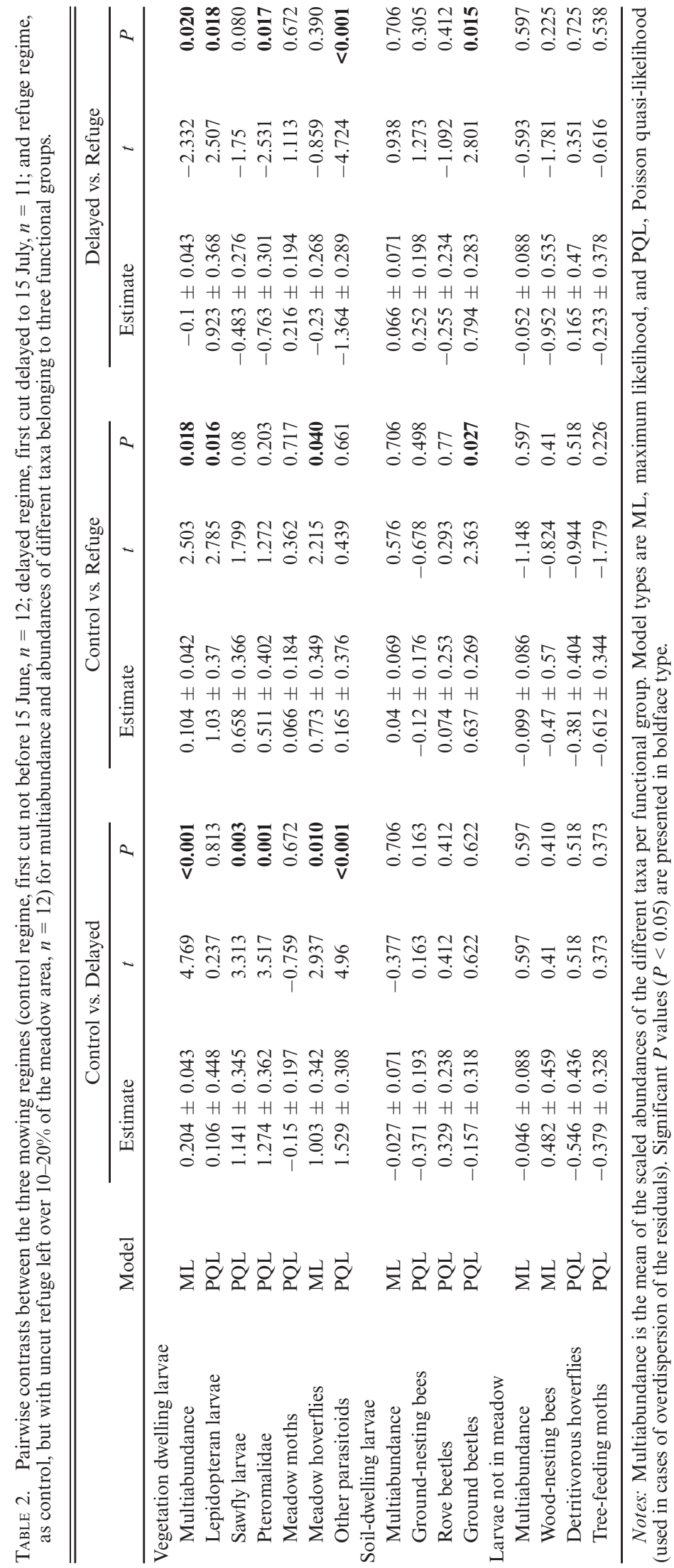


level were excluded from the species richness and traitbased analyses (43 individuals of Lepidoptera, nine wild bees, eight hoverflies and 18 rove beetles).

\section{Community abundance}

For the species with vegetation-dwelling larvae, multiabundance was 2.4 times higher under delayed mowing $(P<0.001)$ and 1.7 times higher $(P=0.018)$ when an uncut grass refuge was left than in the control meadows (Fig. 1, Table 2). Delayed mowing increased multiabundance significantly more than leaving an uncut refuge $(P=0.020)$. At the level of taxonomic groups, this was reflected by a greater abundance of either or both of the alternative mowing regimes in five out of six taxa (Fig. 1, Table 2): Lepidoptera larvae and vegetation-dwelling hoverflies were more abundant in the meadows with an uncut grass refuge than in the control meadows. Sawfly
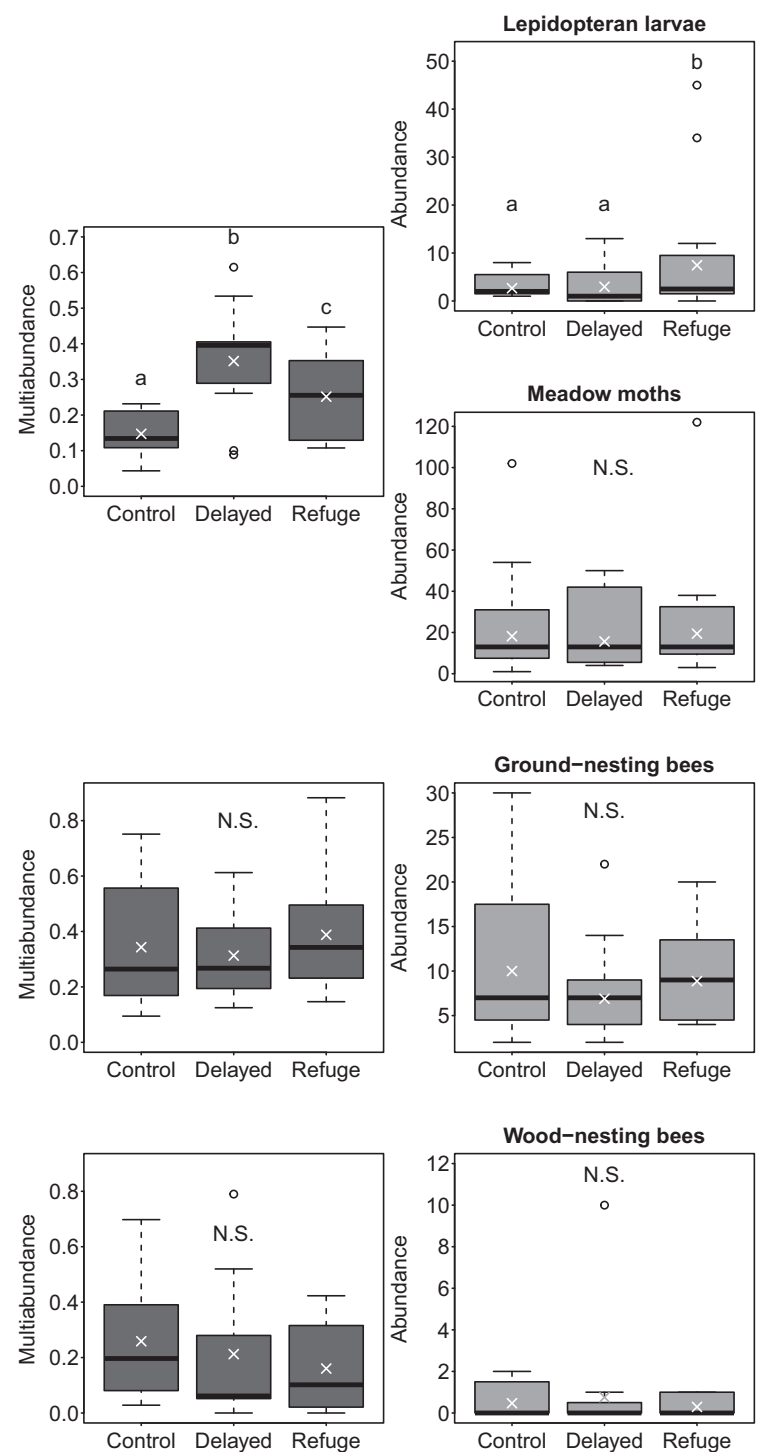
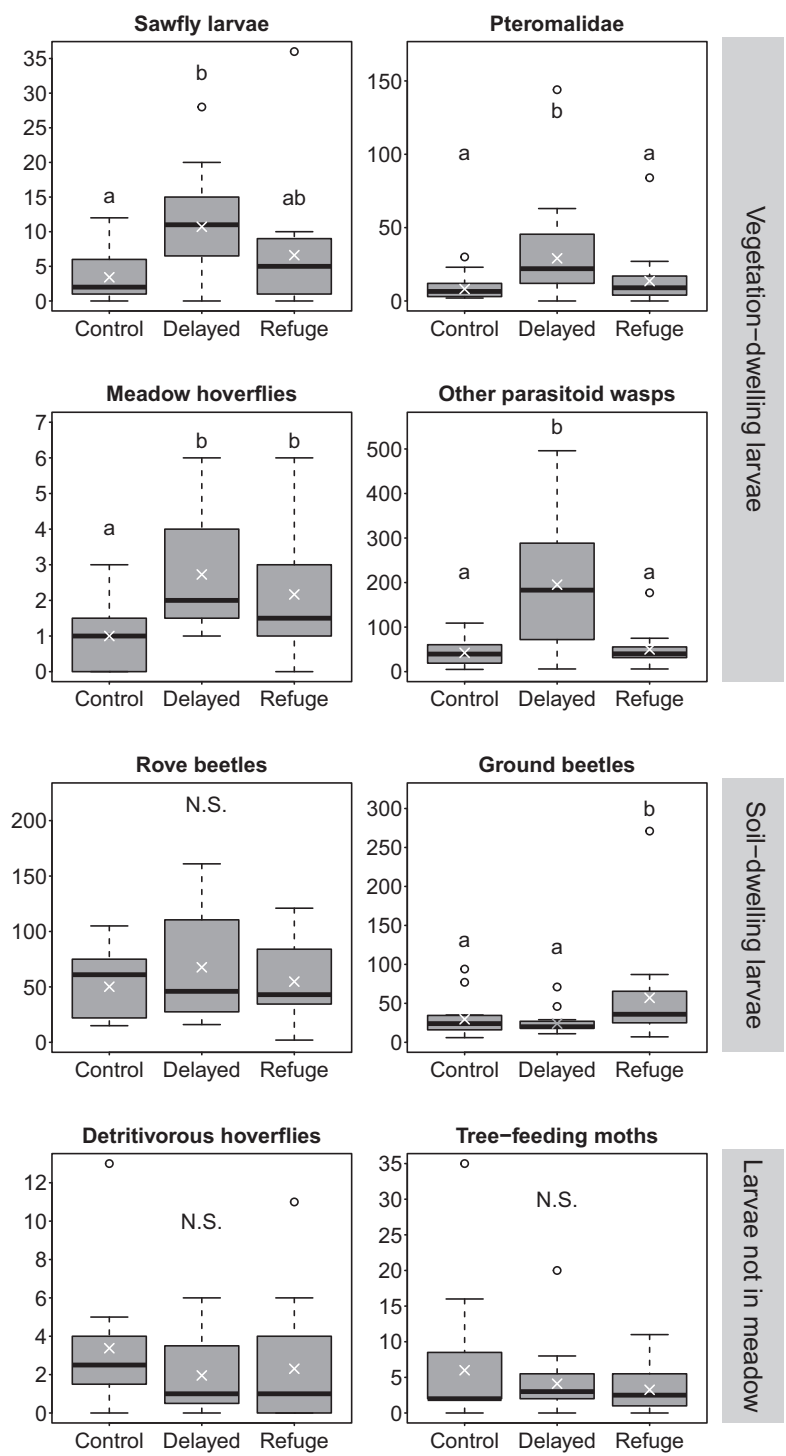

Mowing regime

FIG. 1. Legacy effects of delayed mowing and leaving an uncut grass refuge on the abundance of taxa belonging to three functional groups (indicated by the gray vertical blocks on the right) in comparison to the control mowing regime (first cut not before 15 June). Insects were sampled before the first cut after four (2014) or five (2015) years of experimental manipulation. Multiabundance is the mean of the scaled abundances of the different taxa per functional group. The boxes represent the $25 \%$ and $75 \%$ quartiles from the median (thick line), whiskers represent the maximum and minimum values, excluding outliers, open dots are outliers, defined as values more or less than 1.5 times the interquartile range. Crosses represent model estimates. Differing letters above the boxes represent significant differences $(P<0.05)$, N.S. indicates no significant differences among the mowing regimes. See Table 2 for test statistics. 
larvae, Pteromalidae, other parasitoid wasps and hoverflies were more abundant in the delayed meadows than in the control meadows (Fig. 1, Table 2). Between the two alternative mowing regimes, Lepidopteran larvae were more abundant in the refuge meadows than in the delayed meadows, whereas Pteromalidae and other parasitoid wasps were less abundant. Only moths with vegetationdwelling larvae showed no differences in abundance between any of the regimes. For species with soil-dwelling larvae and species not reproducing in the meadows, no differences in multi-abundance were found (Table 2). Of the taxa with soil-dwelling larvae, only the ground beetles showed higher abundances in the refuge meadows than in the control $(P=0.027)$ and delayed meadows $(P=0.015$; Fig. 1, Table 2), which was caused by one meadow with extremely high abundance. The species groups not reproducing in the meadows showed no differences in their abundances among the mowing regimes (Fig. 1, Table 2). There were few significant relationships between number of uses (mowing and grazing events) or time between the two first cuts in the previous year. Only the abundances of sawfly larvae showed a significantly negative $(t=-2.91, P=0.008)$, and rove beetles a significantly positive $(t=2.17, P=0.044)$ relationships with number of uses. Ground beetle abundances showed a negative relationship with time between cuts $(t=-3.02$, $P=0.017$ ). None of the other taxa, or the functional groups showed any relations with these variables.

\section{Species richness}

Multidiversity was not affected by either of the alternative mowing regimes for any of the functional groups (Fig. 2; Appendix S2: Table S2). Similarly, none of the separate taxa showed differences in species richness between the regimes (Appendix S2: Table S2) or showed a relationship with either number of uses or time between cuts (all $P>0.05$ ).

\section{Species composition and traits}

We found no association between the species composition and the mowing regimes for the species with vegetation-dwelling larvae $(P=1)$ and the species with larvae developing outside the meadow $(P=1)$, but a significant association for the species with ground-dwelling larvae $(P=0.033$; see Appendix S2: Table S3). For species with vegetation-dwelling larvae, the fourth-corner analysis showed a strong association between early phenology and the control meadows (pseudo- $F=-2.383, P=0.005$, $P_{\text {adj }}=0.016$, Table 3). Because the species composition itself was not associated with the mowing regimes, the strong result of this test must be linked to the species traits. We found no associations for the alternative regimes or the other functional groups (Table 3).

Plotting the relationship between the mowing regimes and the abundances of species with an early or late phenology and vegetation-dwelling larvae shows that species with a late phenology were especially abundant in the refuge meadows (pairwise contrasts of PQL regression: control vs. refuge, $z=3.348, P=0.002$; control vs. delayed, $z=0.984, \quad P=0.325 ;$ delayed vs. refuge, $z=2.423, P=0.02$; Fig. 3 ), whereas species with an early phenology (adulthood before June) showed no differences in abundance among regimes (control vs. refuge, $z=0.303, P=0.762$; control vs. delayed, $z=-0.502$, $P=0.762$; delayed vs. refuge, $z=0.798, P=0.762 ; P$ values adjusted by FDR).

\section{Discussion}

Using a trait-based approach, we were able to demonstrate that mowing of hay meadows acts as an ecological filter for the invertebrate community. We found that before any mowing operations took place, taxa with larvae developing in the vegetation column reached higher abundances when mowing in the previous year was experimentally delayed from 15 June to 15 July and/or when a grass refuge of $10-20 \%$ of the meadow area was left uncut (first cut not before 15 June). Yet, species richness did not increase, which only partially supports our first hypothesis. Our results also provide evidence that this positive effect on abundance is probably due to an increased prevalence of species with a later phenology, supporting our second hypothesis. Both alternative mowing regimes enhanced the abundances of species with vegetation-dwelling larvae, which confirms our earlier findings in the same experimental setup (orthopterans: Buri et al. 2013; Auchenorrhyncha and spiders: Buri et al. 2016; butterflies: Bruppacher et al. 2016). Overall, this indicates that habitat quality was indeed enhanced by the alternative mowing regimes, but not to an extent that it allowed additional species to join the community. This may be because colonization by new species requires more time than five years or, alternatively, decades of intensive land use may have purged species with a late phenology from the landscape. Therefore, more drastic measures such as connecting high-quality meadows with ecological corridors and/or assisted colonization may be needed to fully restore former hay meadow biodiversity.

We found little evidence for a relationship between number of cuts or time between cuts and insect abundance or richness. Negative relationship between cutting frequency and insect abundances and diversity have been reported regularly (Helden and Leather 2004, Allan et al. 2014, Uchida and Ushimaru 2014), invariably at higher mowing frequencies (from three cuts per year up to weekly cutting) than employed here. At lower cutting frequencies, results are ambiguous and may differ between insect groups. Abundance and richness of ground dwelling insects as well as flower visitors were found to be highest under two cuts per year (Noordijk et al. 2009, 2010), whereas hemipterans and spiders had higher abundance and richness under one cut per year (Morris and Lakhani 1979, Woodcock et al. 2013), and beetles were unaffected (Morris and Rispin 1987, 

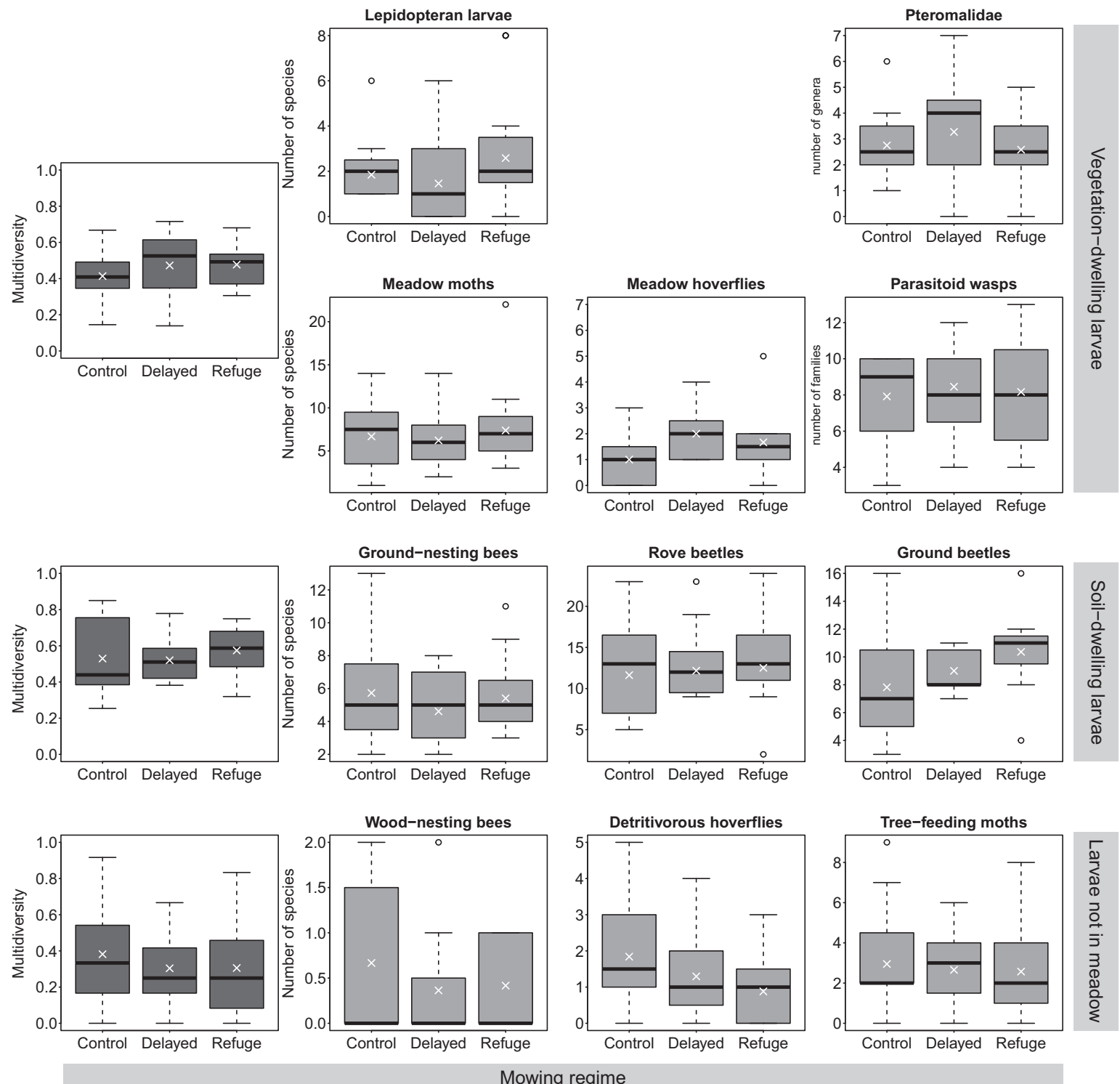

FIG. 2. Responses of species richness and multidiversity of the same taxa and functional groups as in Fig. 1 to the experimental mowing regimes. Multidiversity is the mean of the scaled species richness of the different taxa per functional group. All box plot features and denotation as in Fig. 1. See Appendix S2: Table S2 for test statistics.

Woodcock et al. 2013). The time between cuts has, to our knowledge, only been researched under high cutting frequencies (e.g., Helden and Leather 2004, Halbritter et al. 2015), so that time between cuts was collinear with cutting frequency. In these works, shorter periods between cuts, and thus higher cutting frequencies, had a negative impact on the abundance of butterflies (Halbritter et al. 2015) and hemipterans (Helden and Leather 2004). In our extensively managed meadows located on the Swiss lowland Plateau, which can be seen as representative for most western and central European countries, the timing of the first cut thus seems more important for insects than cutting frequency or time lapse between successive cuts.
Delayed mowing had a positive effect on the next year's abundances of sawfly larvae, hoverflies and parasitoid wasps. This outcome is in line with results from the first years of the experiment, which showed that the abundances of orthopterans (Buri et al. 2013) and spiders (Buri et al. 2016) remained high in the uncut delayed meadows, compared to control meadows mown mid-June (Appendix S2: Table S4). Delaying mowing allows more individuals to reproduce before the first cut, leading to higher abundances in the next spring. This general positive effect of delayed mowing is also supported by previous work (see meta-analysis by Humbert et al. [2012]). These authors showed that insect abundances and richness were higher when cutting was 
TABLE 3. Summary statistics of the fourth-corner analysis for the three insect functional groups.

\begin{tabular}{lcll}
\hline \hline $\begin{array}{l}\text { Mowing } \\
\text { regime }\end{array}$ & \multicolumn{1}{c}{ Pseudo $F$} & \multicolumn{1}{c}{$P$} & \multicolumn{1}{c}{$P_{\text {adj }}$} \\
\hline \multicolumn{4}{l}{ Vegetation-dwelling larvae } \\
Control & -2.383 & $\mathbf{0 . 0 0 5}$ & $\mathbf{0 . 0 1 6}$ \\
Delayed & 1.171 & 0.875 & 0.910 \\
Refuge & 1.364 & 0.910 & 0.910 \\
Soil-dwelling larvae (range of 999 iterations) \\
Control & -0.373 to 0.423 & $0.366-0.672$ & $0.301-0.521$ \\
Delayed & -1.201 to -0.416 & $0.12-0.368$ & $0.177-0.299$ \\
Refuge & $0.345-0.416$ & $0.571-0.861$ & $0.345-0.814$ \\
Larvae not in meadow & & \\
Control & 0.246 & 0.606 & 0.606 \\
Delayed & -0.347 & 0.385 & 0.606 \\
Refuge & 0.214 & 0.595 & 0.606 \\
\hline
\end{tabular}

Notes: We randomized the sites to test for associations between the traits and the mowing regimes. Because there was no association between the raw species composition and the mowing regimes for the species with vegetation dwelling larvae and species with larvae developing outside the meadows, the significant result of this test must be attributed to the traits, not the species. For the species with soil-dwelling larvae, the range of $P$ values is given after running the analysis 999 times to account for the lost traps. $P_{\text {adj }}$ is the $P$ value adjusted by FDR Significant $P$ values $(P<0.05)$ are presented in boldface type.
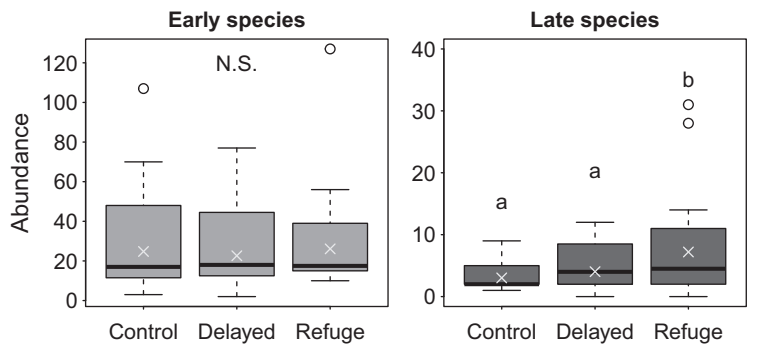

FIG. 3. Abundance of species with vegetation-dwelling larvae with an early (before June) or late (June or later) phenology (i.e., time of start of adult activity). Boxplot properties and denotations as in Fig. 1, crosses represent model estimates.

delayed, which contrasts with the work by Morris and Lakhani (1979) who found that cutting in July was much more detrimental to Hemiptera than cutting in May.

The positive effect of delayed mowing was especially strong for the parasitoid wasps. Parasitoids are rarely assessed in grassland conservation and restoration research, but were presented to be a good indicator taxon in grasslands, showing strong correlations to the richness and abundance of other groups (Anderson et al. 2011). One family of parasitoid wasps, the Pteromalidae, was identified to genus level, providing a unique opportunity to assess which host taxa may have also responded positively to delayed mowing. The most abundant genera found in our meadows were Macroglenes (260 individuals), Mesopolobus (176), Spintherus (78), and Seladerma (53), together representing over $80 \%$ of the individuals caught. Most species of these genera parasitize weevils (Coleoptera: Curculionoidea), gall midges (Diptera: Cecidomyiidae), gall wasps (Hymenoptera: Cynipidae), or stem- or leaf-mining flies, such as Chloropidae and Agromyzidae (Graham 1969, Noyes 2017). All these endophagous host taxa undergo larval development within the vegetation column of grasslands and may have benefited from delayed mowing like the other taxa with vegetation-dwelling larvae, thus dramatically boosting host availability for parasitoid wasps. This corroborates findings about the high sensitivity of endophagous herbivorous insects to grassland management (Sterling et al. 1992, Rothenwöhrer et al. 2013).

Leaving an uncut refuge also enhanced arthropod abundances, but not to the same extent as delayed mowing did. The abundances of Lepidoptera larvae, meadow hoverflies and ground beetles were higher, as well as butterflies (Bruppacher et al. 2016) and orthopterans (Buri et al. 2013), as found in earlier years (Appendix S2: Table S4). This previous work also showed that in the period when the refuges were physically present (after 15 June), insect abundances remained, unsurprisingly, higher inside the refuges than in the mown parts of the meadows, with four times more orthopterans (Buri et al. 2013) and three times more butterflies (Kühne et al. 2015) in the refuges than outside. For the orthopterans, this difference between the refuges and the cut parts decreased over time, suggesting that they recolonized the cut areas within a month (Buri et al. 2013), where they could reproduce and have higher numbers the next spring.

We found evidence for an association between insect species with vegetation dwelling larvae with an early phenology and the control regime, i.e., the regime with the earliest first cut. This suggests that species with a later phenology are almost completely absent from this early mowing regime, and that the delay of mowing operations can especially benefit these species. That we didn't find any associations for the other functional groups may be because they are completely unaffected by the mowing regimes, but three other factors may also play a role: (1) the early sampling date, chosen to avoid measuring the direct effect of mowing, because of which species with a later phenology will be naturally rare; (2) the large number of early species present in all regimes; and (3) the source of the phenological data used (museum collections). Such collections span long periods, thus encompassing a wide range of conditions. As insect phenology is individually variable and also varies with respect to weather and is likely to have advanced with global warming (Parmesan 2007), the averaged values used here may not necessarily reflect the actual conditions encountered during the years of our study. The results of the fourth-corner analysis are supported by the partitioning into early and late phenology species, the latter occurring only scarcely in the control meadows. We thus conclude that there is an association between species with a later phenology and our alternative mowing regimes, which provides evidence for a 
community filtering mechanism induced by mowing operations.

Our experimental trait-based approach showed how the date of mowing modulates invertebrate community assembly in hay meadows. Trait-based research has grown exponentially over the past decades, but recently concern has been raised because many studies are insufficiently hypothesis-driven or supported by theory, notably those on invertebrates (Verberk et al. 2013, Didham et al. 2016). Our work shows that when applied in an experimental, hypothesis-driven framework, trait-based approaches can lead to important insights into the mechanisms of community structuring processes and biodiversity patterns. Although it has been argued that functional traits should be measureable at the level of individual organisms (McGill et al. 2006), our findings demonstrate that population-aggregated traits, such as phenology, can also help deciphering community assembly rules.

In line with the previous research carried out in the same experimental setup (Appendix S2: Table S4), our results confirm that even slight modifications to hay meadow management can have significant positive effects on arthropod abundances. Enhanced insect abundances will decrease extinction risks, and will provide more food to insectivorous vertebrates, such as birds and bats. Although the present study showed no effects of the alternative mowing regimes on species richness, our former studies showed positive effects for orthopterans and specialist butterflies.

Delaying mowing and leaving an uncut grass refuge during hay making operations, as experimentally tested here, are measures that could be easily implemented in European agri-environment schemes and the newly launched EU Ecological Focus Areas designed to improve farmland biodiversity (see Pe'er et al. 2016). In contrast, the number of cuts and time between cuts in extensively managed meadows (with no fertilizer input) had little to no effect on the invertebrate community, suggesting that these factors are irrelevant for designing future agri-environment schemes. Improving the invertebrate biodiversity of grasslands, both in terms of species richness and abundance, is indeed key, and will not only promote species providing crucial ecological functions and ecosystem services (e.g., pest control and pollination) but also re-instate integrative food chains that allow insectivorous vertebrates to retrieve their place within agro-ecosystems.

\section{Acknowledgments}

We thank Chantal Herzog and Claudia Blumenstein for help with the field work, and Werner Marggi and Sabine Oertli for help with the identifications, all involved farmers for their collaboration, Markus Fischer, Pierrick Buri, and Jérôme Pellet for co-initiating and setting up this project. Four reviewers helped to improve the quality of the paper. This work was funded by the Swiss National Science Foundation (grants 31003A_125398/2 and 31003A_149656 to R. Arlettaz), the Federal Offices for the Environment and for Agriculture, and the cantons of Aargau, Bern, Basel-Land, Fribourg, Neuchâtel, and Vaud.

\section{Literature Cited}

Allan, E., et al. 2014. Interannual variation in land-use intensity enhances grassland multidiversity. Proceedings of the National Academy of Sciences USA 111:308-313.

Amiet, F., M. Herrmann, A. Müller, and R. Neumeyer. 1996. Fauna Helvetica apidae band 1-6. Centre Suisse de Cartographie de la Faune \& Schweizerische Entomologische Gesellschaft, Neuchatel, Switzerland.

Anderson, A., S. McCormack, A. Helden, H. Sheridan, A. Kinsella, and G. Purvis. 2011. The potential of parasitoid Hymenoptera as bioindicators of arthropod diversity in agricultural grasslands. Journal of Applied Ecology 48:382390.

Arlettaz, R. 1996. Feeding behaviour and foraging strategy of free-living mouse-eared bats, Myotis myotis and Myotis blythii. Animal Behaviour 51:1-11.

Bakker, J. P. 1989. Nature management by cutting and grazing. Kluwer Academic Publishers, Dordrecht, The Netherlands.

Bates, D., M. Maechler, B. Bolker, and S. Walker. 2014. lme4: Linear mixed-effects models using Eigen and S4_. R package version 1.1-7. https://cran.r-project.org/web/packages/lme4

Benjamini, Y., and Y. Hochberg. 1995. Controlling the false discovery rate - a practical and powerful approach to multiple testing. Journal of the Royal Statistical Society Series B: Methodological 57:289-300.

Birkhofer, K., T. Diekötter, C. Meub, K. Stötzel, and V. Wolters. 2015. Optimizing arthropod predator conservation in permanent grasslands by considering diversity components beyond species richness. Agriculture, Ecosystems and Environment 211:65-72.

Blake, S., G. N. Foster, M. D. Eyre, and M. L. Luff. 1994. Effects of habitat type and grassland management-practices on the body-size distribution of carabid beetles. Pedobiologia 38:502-512.

Bruppacher, L., J. Pellet, R. Arlettaz, and J.-Y. Humbert. 2016. Simple modifications of mowing regime promote butterflies in extensively managed meadows: Evidence from field-scale experiments. Biological Conservation 196:196-202.

Buri, P., R. Arlettaz, and J.-Y. Humbert. 2013. Delaying mowing and leaving uncut refuges boosts orthopterans in extensively managed meadows: Evidence drawn from field-scale experimentation. Agriculture, Ecosystems and Environment 181:22-30.

Buri, P., J. Y. Humbert, M. Stańska, I. Hajdamowicz, E. Tran, M. H. Entling, and R. Arlettaz. 2016. Delayed mowing promotes planthoppers, leafhoppers and spiders in extensively managed meadows. Insect Conservation and Diversity 9:536545.

Callaham, M. A., M. R. Whiles, and J. M. Blair. 2002. Annual fire, mowing and fertilization effects on two cicada species (Homoptera: Cicadidae) in tallgrass prairie. American Midland Naturalist 148:90-101.

Cardarelli, E., and G. Bogliani. 2014. Effects of grass management intensity on ground beetle assemblages in rice field banks. Agriculture, Ecosystems and Environment 195:120 126.

Devereux, C. L., M. J. Whittingham, J. R. Krebs, E. FernándezJuricic, and J. A. Vickery. 2006. What attracts birds to newly mown pasture? Decoupling the action of mowing from the provision of short swards. Ibis 148:302-306.

Didham, R. K., S. R. Leather, and Y. Basset. 2016. Circle the bandwagons - challenges mount against the theoretical 
foundations of applied functional trait and ecosystem service research. Insect Conservation and Diversity 9:1-3.

Dray, S., and A. Dufour. 2007. The ade4 package: implementing the duality diagram for ecologists. Journal of Statistical Software 22:1-20.

Dray, S., and P. Legendre. 2008. Testing the species traits-environment relationships: The fourth-corner problem revisited Ecology 89:3400-3412.

Ebert, G., et al. 1994. Die Schmetterlinge Baden-Württembergs Band 3-9. Ulmer, Stuttgart, Germany.

Gardiner, T., and M. Hassall. 2009. Does microclimate affect grasshopper populations after cutting of hay in improved grassland? Journal of Insect Conservation 13:97-102.

Gossner, M. M., et al. 2016. Land-use intensification causes multitrophic homogenization of grassland communities. Nature 540:266-269.

Goulet, H., and J. T. Huber. 1993. Hymenoptera of the world: an identification guide to families. Canada Communication Group Publishing, Ottawa, Ontario, Canada.

Graham, M. W. 1969. The pteromalidae of North-Western Europe the British museum (natural history). Bulletin of the British Museum (Natural History) Entomology Supplement 16:1-909.

Grundel, R., K. J. Frohnapple, R. P. Jean, and N. B. Pavlovic. 2011. Effectiveness of bowl trapping and netting for inventory of a bee community. Environmental Entomology 40:374-380.

Halbritter, D. A., J. C. Daniels, D. C. Whitaker, and L. Huang. 2015. Reducing mowing frequency increases floral resource and butterfly (Lepidoptera: Hesperioidea and Papilionoidea) abundance in managed roadside margins. Florida Entomologist 98:1081-1092.

Helden, A. J., and S. R. Leather. 2004. Biodiversity on urban roundabouts - Hemiptera, management and the species-area relationship. Basic and Applied Ecology 5:367-377.

Humbert, J.-Y., J. Ghazoul, and T. Walter. 2009. Meadow harvesting techniques and their impacts on field fauna. Agriculture, Ecosystems \& Environment 130:1-8.

Humbert, J.-Y., J. Ghazoul, N. Richner, and T. Walter. $2010 a$. Hay harvesting causes high orthopteran mortality. Agriculture, Ecosystems and Environment 139:522-527.

Humbert, J.-Y., J. Ghazoul, G. J. Sauter, and T. Walter. $2010 b$. Impact of different meadow mowing techniques on field invertebrates. Journal of Applied Entomology 134:592-599.

Humbert, J.-Y., J. Pellet, P. Buri, and R. Arlettaz. 2012. Does delaying the first mowing date benefit biodiversity in meadowland? Environmental Evidence 1:9.

Keddy, P. A. 1992. Assembly and response rules: two goals for predictive community ecology. Journal of Vegetation Science 3:157-164.

Kleijn, D., et al. 2009. On the relationship between farmland biodiversity and land-use intensity in Europe. Proceedings of the Royal Society B 276:903-909.

Kühne, I., R. Arlettaz, J. Pellet, L. Bruppacher, and J. Humbert. 2015. Leaving an uncut grass refuge promotes butterfly abundance in extensively managed lowland hay meadows in Switzerland. Conservation Evidence 12:25-27.

Lafage, D., and J. Pétillon. 2014. Impact of cutting date on carabids and spiders in a wet meadow. Agriculture, Ecosystems \& Environment 185:1-8.

Legendre, P., R. Galzin, and M. L. Harmelin-Vivien. 1997. Relating behavior to habitat: solutions to the fourth-corner problem. Ecology 78:547-562.

Löbbert, M., K.-H. Kromer, and C. C. Wieland. 1994. Einfluss von Mäh- und Mulchgeräten auf die bodennahe Fauna. Forschungsberichte "Integrative Extensivierungs- und Naturschutzstrategien." 15:7-26.
Luka, H., W. Marggi, C. Huber, Y. Gonseth, and P. Nagel. 2009. Coleoptera, Carabidae. Ecology atlas. Fauna Helvetica 24. Centre Suisse de Cartographie de la Faune \& Schweizerische Entomologische Gesellschaft, Neuchâtel, Switzerland.

Maibach, A., P. Goeldlin de Tiefenau, and H. Dirckx. 1992. Liste faunistique des Syrphidae de Suisse (Diptera). Centre Suisse de Cartographie de la Faune, Neuchâtel, Switzerland.

McGill, B. J., B. J. Enquist, E. Weiher, and M. Westoby. 2006. Rebuilding community ecology from functional traits. Trends in Ecology \& Evolution 21:178-185.

Meyer, S., D. Unternährer, R. Arlettaz, J.-Y. Humbert, and M. H. M. Menz. 2017. Promoting more diverse communities of wild bees and hoverflies requires a landscape approach to managing meadows. Agriculture, Ecosystems \& Environment 239:376-384.

Morris, M. G., and K. H. Lakhani. 1979. Responses of grassland invertebrates to management by cutting I. Species diversity of Hemiptera. Journal of Applied Ecology 16:77-98.

Morris, M. G., and W. E. Rispin. 1987. Abundance and diversity of the coleopterous fauna of a calcareous Grassland under different cutting regimes. Journal of Applied Ecology 24:451-465.

Noordijk, J., K. Delille, A. P. Schaffers, and K. V. Sýkora. 2009. Optimizing grassland management for flower-visiting insects in roadside verges. Biological Conservation 142: 2097-2103.

Noordijk, J., A. P. Schaffers, T. Heijerman, P. Boer, M. Gleichman, and K. V. Sýkora. 2010. Effects of vegetation management by mowing on ground-dwelling arthropods. Ecological Engineering 36:740-750.

Noyes, J. 2017. Universal Chalcidoidea Database. http://www. nhm.ac.uk/chalcidoids

Oksanen, J., et al. 2017. vegan 2.4-4. Community Ecology Package. http://CRAN.R-project.org/package=vegan

Parmesan, C. 2007. Influences of species, latitudes and methodologies on estimates of phenological response to global warming. Global Change Biology 13:1860-1872.

Pe'er, G., et al. 2016. Adding some green to the greening: Improving the EU's ecological focus areas for biodiversity and farmers. Conservation Letters 10:517-530.

Reemer, M., W. Renema, W. van Steenis, T. Zeegers, A. Barendregt, J. T. Smit, M. P. van Veen, J. van Steenis, and L. J. J. M. van der Leij. 2009. De Nederlandse Zweefvliegen. KNNV Uitgeverij, Zeist, The Netherlands.

Rothenwöhrer, C., C. Scherber, and T. Tscharntke. 2013. Grassland management for stem-boring insects: Abandoning small patches is better than reducing overall intensity. Agriculture, Ecosystems \& Environment 167:38-42.

Simons, N. K., W. W. Weisser, and M. M. Gossner. 2017. Multitaxa approach shows consistent shifts in arthropod functional traits along grassland land-use intensity gradient. Ecology 97:754-764

Sterling, P. H., C. W. D. Gibson, and V. K. Brown. 1992. Leaf miner assemblies - effects of plant succession and grazing management. Ecological Entomology 17:167-178.

Uchida, K., and A. Ushimaru. 2014. Biodiversity declines due to abandonment and intensification of agricultural lands: Patterns and mechanisms. Ecological Monographs 84:637658.

Uchida, K., and A. Ushimaru. 2015. Land abandonment and intensification diminish spatial and temporal $\beta$-diversity of grassland plants and herbivorous insects within paddy terraces. Journal of Applied Ecology 52:1033-1043.

Van Klink, R., S. Boch, P. Buri, N. S. Rieder, J.-Y. Humbert, and R. Arlettaz. 2017. No detrimental effects of delayed mowing or uncut grass refuges on plant and bryophyte 
community structure and phytomass production in low-intensity hay meadows. Basic and Applied Ecology 20:1-9.

Venables, W. N., and B. D. Ripley. 2002. Modern applied statistics with S. Fourth edition. Springer, New York, New York, USA.

Verberk, W. C. E. P., C. G. E. van Noordwijk, and A. G. Hildrew. 2013. Delivering on a promise: integrating species traits to transform descriptive community ecology into a predictive science. Freshwater Science 32:531-547.

Völkl, W., H. Zwölfer, M. Romstöck-Völkl, and C. Schmelzer. 1993. Habitat management in calcareous grasslands: effects on the insect community developing in flower heads of Cynarea. Journal of Applied Ecology 30:307-315.

Wan, S., Y. Luo, and L. L. Wallace. 2002. Changes in microclimate induced by experimental warming and clipping in tallgrass prairie. Global Change Biology 8:754-768.

Westrich, P. 1989. Die Wildbienen Baden-Württembergs (Teil I und II). Ulmer, Stuttgart, Germany.
Williamson, C. R., and D. A. Potier. 1997. Oviposition of black cutworm (Lepidoptera: Noctuidae) on creeping bentgrass putting greens and removal of eggs by mowing. Journal of Economic Entomology 90:590-594.

Woodcock, B. A., S. G. Potts, T. Tscheulin, E. Pilgrim, A. J. Ramsey, J. Harrison-Cripps, V. K. Brown, and J. R. Tallowin. 2009. Responses of invertebrate trophic level, feeding guild and body size to the management of improved grassland field margins. Journal of Applied Ecology 46:920-929.

Woodcock, B. A., J. Savage, J. M. Bullock, M. Nowakowski, R. Orr, J. R. B. Tallowin, and R. F. Pywell. 2013. Enhancing beetle and spider communities in agricultural grasslands: The roles of seed addition and habitat management. Agriculture, Ecosystems and Environment 167:79-85.

Woodward, F. I., and A. D. Diament. 1991. Functional approaches to predicting the ecological effects of global change. Functional Ecology 5:202-212.

\section{SUPPORTING INFORMATION}

Additional supporting information may be found online at: http://onlinelibrary.wiley.com/doi/10.1002/eap.1900/full 